\title{
Adverse Childhood Experiences and Health in Adulthood in a Rural Population-Based Sample
}

\author{
Kristen C. Iniguez, DO and Rachel V. Stankowski, PhD
}

\begin{abstract}
Background: Adverse childhood experiences (ACEs), including emotional abuse, substance abuse in the household, separation or divorce, physical abuse, violence between adults, mental illness in the household, sexual abuse, or incarceration of a household member, have the potential to profoundly impact health and well-being in adulthood. To assess whether previously reported relationships between ACEs and health outcomes withstand validation, we conducted a community-based ACE study with the unique capacity to link self-reported ACEs and other survey results to validated health data in an electronic medical record (EMR).
\end{abstract}

Methods: Information regarding ACEs and health outcomes was captured from 20I3-20I4 via a telephone survey of residents of the predominantly rural northern and central regions of Wisconsin and electronic abstraction of EMR data. ACE score was calculated by counting each exposure as one point. We examined the relationship between ACE score, type, and self-reported and validated health outcomes.

Results: A total of 800 participants completed the telephone survey. Overall, $62 \%$ reported at least one ACE and I5\% reported experiencing four or more.All self-reported measures of poor health were associated with increased ACE score. EMR data were positively correlated with ACE score for increased body mass index and diagnoses of depression, anxiety, and asthma. In contrast, diagnoses of hypertension, hypercholesterolemia, myocardial infarction, and skin and other cancers were inversely related to ACE score. Emotional abuse was the most common ACE reported followed by substance abuse in the household. ACEs tended to cluster so that people who reported at least one ACE were likely to have experienced multiple ACEs. There was no clear correlation between abuse type (e.g., direct abuse vs. household dysfunction) and health outcomes.

Conclusions: In the first community-based study to link self-reported ACEs to comprehensive health measures documented in the medical record, we observed previously reported associations between childhood adversity and poor outcomes in adulthood, but also noted an inverse relationship between ACE score and certain medical diagnoses. Potential explanations for this finding warrant further investigation.

Keywords: Adverse childhood experience; Health outcomes; Adult health; Rural

A dverse childhood experiences (ACEs) have the potential to profoundly impact the cognitive, social, and neurobiologic functioning of developing brains..$^{1,2}$ Studies of ACEs, including the first such study published in 1998 by Felitti et al, ${ }^{3}$ typically focus on issues of abuse, including physical, sexual, and emotional abuse, and household dysfunctions, including substance abuse, separation or divorce, violence between adults, mental illness, and incarceration. Additional peer- and community-related factors

Corresponding Author: Kristen C. Iniguez, DO, 1000 N Oak Ave, Marshfield, WI 54449 USA, Phone: (7I5) 389-5008, Fax: (7I5) 389-5003,

E-mail: iniguez.kristen@marshfieldclinic.org may also warrant consideration as harmful childhood adversities, ${ }^{4}$ and recent studies have begun to assess an expanded definition of adversity. ${ }^{5,6}$ Regardless of the ACEs examined, evidence suggests that an increasing number of adverse experiences during childhood corresponds to worsening physical and mental health outcomes in adulthood ${ }^{7-16}$ and intergenerational cycles of ACE-related mental health, behavioral, and social problems. ${ }^{17}$
Received: September 22, 2015

Ist Revision: May 18, 2016

2nd Revision: June 23, 2016

Accepted: July I, 2016

doi: $10.3|2| / \mathrm{cmr} .2016 .1306$

Financial disclosure: This work was funded by a generous grant from the Marshfield Clinic Research Foundation (SP no. INII0II2). 
Results of the first ACE study published in 1998 demonstrated a clear, graded relationship between the number of ACEs a person reported and several health risk behaviors and diseases. ${ }^{3}$ ACEs were found to be strongly interrelated and additive, whereby a person reporting multiple ACEs was likely to report the presence of multiple health risk behaviors during adulthood. As such, an optional ACE module was incorporated into the Centers for Disease Control and Prevention (CDC) Behavioral Risk Factors Surveillance System (BRFSS) questionnaire and results have been reported for several states. ${ }^{13,18}$ The majority of studies published regarding the association between ACEs and adverse health outcomes in adults, including those based on the BRFSS questionnaire, relied largely on self-report or cross-sectional analysis of data captured at a single time point. . $^{70-12,14-16}$ However, longitudinal follow-up of the original ACE study performed by Felitti et $\mathrm{al}^{3}$ has allowed for abstraction of additional, validated data related to prescriptions, diseases (e.g., chronic obstructive pulmonary disease, autoimmune disease, lung cancer), and mortality in a subset of more than 15,000 patients. ${ }^{19-23}$ Similarly, population-based Swedish cohort studies have longitudinally linked measurable indicators of childhood household dysfunction with poor mental health outcomes and psychotropic medication use $\mathrm{e}^{8,9}$ and the long-term British National Child Development Study found a link between ACEs and cancer risk in adulthood as well as premature all-cause mortality. ${ }^{24,25}$ However, no study to date has linked ACE data to comprehensive health data captured over time from a community-based sample. Here, we performed a telephone survey to assess ACEs and other self-reported measures in residents of northern and central Wisconsin with consent to access comprehensive patient data available in an electronic medical record (EMR). Data captured were used to assess whether previously reported relationships between ACEs and adverse health outcomes withstand validation. To our knowledge, this is the first rural, community-based ACE study with the unique capacity to link self-reported ACE survey results with comprehensive, validated health outcomes data in the EMR.

\section{Methods}

Population

Information regarding ACEs and health outcomes was captured via telephone survey and electronic abstraction of data from the Marshfield Clinic EMR. Telephone surveys were administered from 2013-2014 to Marshfield Epidemiologic Study Area (MESA) residents 18 years of age and older using a sampling technique representative of the patient population of the Marshfield Clinic, a large, independent, nonprofit clinic providing regional medical care at over 50 locations in northern, central, and western Wisconsin. MESA includes residents of a 24-ZIP code region in northern and central Wisconsin in which the majority of residents choose to receive medical care within the Marshfield Clinic system. ${ }^{26}$ MESA consists of approximately 60,000 residents in 14 ZIP codes clustered around the city of Marshfield, Wisconsin, making up MESA Central and an additional approximately 25,000 people in 10 ZIP codes near Park Falls, Phillips, and Ladysmith in northern Wisconsin, making up MESA North. ${ }^{27}$ The population is predominantly rural, Caucasian, and considered medically underserved and economically disadvantaged. ${ }^{27}$

Potential study participants were identified by randomly selecting MESA residents 18 years of age or older to receive introductory letters followed by telephone calls. Equal numbers of subjects from each MESA region were recruited. Information gathered on all randomly selected MESA residents before study start included name, address, phone number, gender, and date of birth. This initial information was used to compare responders and non-responders at study end. Introductory letters were sent to addresses on file for all potential subjects, and follow-up telephone calls were made by research coordinators to assess willingness to participate. Research coordinators making telephone calls followed a telephone script (Appendix 1, available online) to establish subject identity, ensure study eligibility (not diagnosed with Alzheimer's disease, English speaking, still reside in MESA area), provide explanation of the study, and capture consent to participate before administering survey questions. This study was approved by the Marshfield Clinic Institutional Review Board (protocol \#INI10112; 12/12/2012), and informed consent for study participation and access to the EMR was obtained for all participants.

\section{Measures}

Telephone survey questions were scripted according to the 2011 BRFSS questionnaire (http:/www.cdc.gov/brfss/ questionnaires.htm). ${ }^{18}$ Modifications to the questionnaire as written were made in the interest of brevity while ensuring that information relevant to the current study was captured. For study purposes, we used the majority of the core module to garner information regarding behaviors that affect health and questions on demographic characteristics that are not available in the EMR. We also used two optional modules regarding (1) emotional support and life satisfaction and (2) adverse childhood experiences. The complete telephone survey script can be found in Appendix 1 (available online). With respect to questions about ACEs, participants were asked to consider specifically the period of time before they were 18 years of age.

Cumulative exposure to ACEs is measured using the ACE score, which counts each exposure as one point without taking into account the frequency or severity of any given ACE during a person's lifetime. Additional data collected electronically from the EMR for patients who agreed to study participation included most recent height and weight and several chronic health conditions [hypertension, hypercholesterolemia, diabetes, myocardial infarction, heart disease, stroke, asthma, skin cancer, other cancer, chronic obstructive pulmonary disease, emphysema, chronic bronchitis, arthritis or related condition (rheumatoid arthritis, lupus, gout, fibromyalgia, rheumatism, polymyalgia 
Table 1. Survey respondent demographics

\begin{tabular}{|c|c|}
\hline & $\mathrm{n}(\%)$ \\
\hline \multicolumn{2}{|l|}{ Age (years) } \\
\hline $18-34$ & $135(17)$ \\
\hline $35-49$ & $126(16)$ \\
\hline $50-64$ & $226(28)$ \\
\hline$\geq 65$ & $317(39)$ \\
\hline \multicolumn{2}{|l|}{ Gender } \\
\hline Male & $339(42)$ \\
\hline Female & $465(58)$ \\
\hline \multicolumn{2}{|l|}{ Ethnicity } \\
\hline Non-Hispanic White & $748(99)$ \\
\hline Hispanic or Latino & $6(1)$ \\
\hline \multicolumn{2}{|l|}{ Race } \\
\hline White & $748(98.4)$ \\
\hline Asian & $2(0.3)$ \\
\hline Native Hawaiian or Other Pacific Islander & $1(0.1)$ \\
\hline American Indian or Alaska Native & $3(0.4)$ \\
\hline Other & $6(0.8)$ \\
\hline \multicolumn{2}{|l|}{ Annual Household Income } \\
\hline$<\$ 25,000$ & $237(32)$ \\
\hline$\$ 25,000-34,999$ & $126(17)$ \\
\hline$\$ 35,000-49,999$ & $137(19)$ \\
\hline$\$ 50,000-74,999$ & $128(17)$ \\
\hline$\geq \$ 75,000$ & $104(14)$ \\
\hline \multicolumn{2}{|l|}{ Education } \\
\hline$<$ High School & $68(9)$ \\
\hline High School & $274(34)$ \\
\hline Some College & $245(32)$ \\
\hline College Degree + & $200(25)$ \\
\hline \multicolumn{2}{|l|}{ Health Insurance } \\
\hline Private/Medicare & $674(86)$ \\
\hline None & $23(3)$ \\
\hline Medicaid/BadgerCare & $91(12)$ \\
\hline \multicolumn{2}{|l|}{ Employment } \\
\hline Employed & $365(48)$ \\
\hline Out of Work & $81(11)$ \\
\hline $\begin{array}{c}\text { Retired } \\
\text { Medical Diagnoses }\end{array}$ & $318(42)$ \\
\hline Hypertension & $402(50)$ \\
\hline Hypercholesterolemia & $374(47)$ \\
\hline Myocardial Infarction & $63(8)$ \\
\hline Diabetes & $147(18)$ \\
\hline Heart Disease & $342(43)$ \\
\hline Stroke & $47(6)$ \\
\hline Asthma & $153(19)$ \\
\hline Skin Cancer & $83(10)$ \\
\hline Other Cancer & $217(27)$ \\
\hline Chronic obstructive pulmonary disease & $73(9)$ \\
\hline Emphysema & $20(2)$ \\
\hline Chronic Bronchitis & $63(8)$ \\
\hline Arthritis or Related Condition & $578(72)$ \\
\hline Depressive Disorder(s) & $272(34)$ \\
\hline Anxiety Disorders & 231 (29) \\
\hline
\end{tabular}

Note: Health insurance, ethnicity, and race captured by self-report; all other variables abstracted electronically from the electronic medical record. rheumatic, osteoarthritis, tendonitis, bursitis, bunion, tennis elbow, carpal tunnel syndrome, tarsal tunnel syndrome, joint infection, Reiter's syndrome, ankylosing spondylitis, spondylitis, rotator cuff syndrome, connective tissue disease, scleroderma, polymyositis, Raynaud's syndrome, vasculitis, giant cell arteritis, Henoch-Schonlein purpura, Wegener's granulomatosis, polyarteritis nodosa), depressive disorders, and anxiety disorders] identified by International Classification of Disease, Version 9 (ICD-9) code. A participant was categorized as having a given condition if the associated ICD-9 code appeared at least two times in the EMR.

Statistical analyses focused on characterizing the correlation between ACE score and health outcomes in adulthood. Descriptive statistics are reported for participant demographic characteristics. Basic attributes captured electronically before study consent, including age, gender, and MESA residence region, were compared between survey responders and nonresponders. Comparisons were carried out using Fisher's exact or Chi-square tests as appropriate. In the analysis of the responders, we focused on reporting the percentage of ACEs with and without stratifying by total ACE score, age group, gender, and ACE type. Relationships between ACE scores and defined physical and mental well-being outcomes were determined by calculating Spearman's correlation coefficients and corresponding $P$-values. $P$-values of less than 0.05 were considered statistically significant. Analyses were carried out using the commercially available statistical software package SAS (Version 9.2, English).

\section{Results}

A total of 6,514 phone calls were made to enroll 800 subjects with completed telephone surveys: 419 (6.4\%) potential subjects had phone numbers out of service; 2,768 (42.5\%) were unreachable by the third phone call; 582 (8.9\%) were ineligible (diagnosed with Alzheimer's disease, non-English speaking, moved out of MESA areas); and 1,941 (29.8\%) declined to participate. A total of 804 (12.3\%) subjects consented to participate, 800 of whom completed the entire telephone survey. An equal number of participants who completed the survey came from each MESA region. Those who declined to participate $(\mathrm{n}=1,941)$ were more likely to be male $(P=0.0048)$ and MESA Central residents $(P=0.0423)$ compared to those who participated. Age distribution did not differ between responders and non-responders.

Survey respondent demographics are shown in Table 1. Overall, $62 \%$ of participants reported experiencing at least one $\mathrm{ACE}$ and $15 \%$ reported experiencing four or more ACEs in their lifetime (Table 2). Distribution of ACE scores by subject demographics, self-reported health measures, and validated diagnoses are shown in Table 2. Distribution suggests that respondents age 65 years and older were less likely to report ACEs than younger participants, but there was no difference by gender. Though not significant, as income level increased, the percentage of individuals reporting four or more ACEs progressively decreased (Table 2). Similarly, significantly 
more respondents with ACE scores of four or more reported being out-of-work, and a higher proportion of such respondents were also receiving public assistance in the form of Medicaid or BadgerCare rather than private insurance or Medicare (Table 2).

All self-reported measures of increased health risk and poor health outcomes were associated with increased ACE score, including lack of emotional support, dissatisfaction with life, poor general and physical health, occurrence of frequent mental distress, limitations caused by mental or physical health issues, smoking, and heavy drinking (Table 2). This was consistent with validated findings from the EMR showing a strong positive correlation between mental health outcomes and increasing number of ACEs, including diagnosis of depression or anxiety (Table 2). While a similar relationship was observed for self-reported measures of physical health, it was interesting to note that when ACE score distribution was assessed with respect to health outcomes reported in the EMR, increased body mass index (BMI) and asthma were the only conditions that consistently increased with increasing ACE score. In contrast, diagnosis of hypertension, hypercholesterolemia, myocardial infarction, or skin and other cancers displayed an inverse relationship with ACE score, whereby the percentage of subjects diagnosed with each condition significantly decreased with increasing ACE score (Table 2).

Results broken down by individual ACE are shown in Figure 1. Emotional abuse was the most commonly reported ACE, followed by substance abuse in the household. Age differences in ACE reporting persisted when broken down by individual ACE for all ACEs except incarceration of a household member. In addition, gender differences emerged. Gender differences for individual ACEs were reported for physical abuse $(P=0.0022)$, sexual abuse $(P=0.0001)$, and mental illness in the household $(P=0.0076)$, with female respondents reporting all three ACEs more often than male respondents. This was particularly striking for sexual abuse with $21.1 \%$ of females and $10.9 \%$ of males reporting sexual abuse during childhood.

Adverse childhood experiences tended to occur in clusters, such that people who reported experiencing at least one ACE were likely to have experienced multiple ACEs. Approximately $24 \%$ of adults who experienced at least one ACE had four or more compared to $15 \%$ in the general population. Certain ACEs tended to indicate a greater likelihood of other traumatic experiences in childhood (Figure 2). The occurrence of four or more ACEs was most common in subjects who reported incarceration of a household member, violence between adults, and physical abuse. However, the presence of four or more ACEs was considerably greater in individuals reporting any ACE than in the overall surveyed population (36.5-61.8\% vs. $15.2 \%$, Figure 2 ). Chi-square testing revealed significant relationships between nearly all possible ACE combinations.
To assess whether certain types of ACEs impacted measures of health and well-being differently, ACEs were separated into two categories, including direct abuse (emotional, physical, and sexual abuse) and household dysfunction (mental illness, incarceration, violence, substance abuse, divorce/separation), and the relationship between abuse type and health outcomes were examined (Table 3 ). Results were similar to those with ACE score. However, one additional relationship of interest between report of household dysfunction and chronic bronchitis emerged.

\section{Discussion}

Adverse experiences during childhood can have a profound impact on health and well-being in adulthood. Recognizing the importance of this relationship, the CDC incorporated an optional ACE module into the BRFSS questionnaire and several states have since published ACE study results using these data. ${ }^{13,18,28}$ These and other studies of childhood adversity from the US and around the world using a variety of data sources clearly demonstrate that ACEs are linked to poorer social, economic, behavioral, and physical health outcomes in

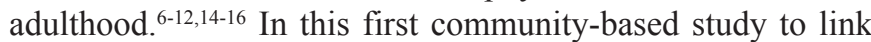
self-reported ACEs to comprehensive health measures documented in the medical record, we also demonstrated a link between childhood adversity and poor outcomes in adulthood, but found that for a number of specific medical diagnoses, findings were inconsistent with previous reports.

The uniqueness of the present study is related primarily to its data collection methods and ability to link reports from a community-based population regarding childhood adversity to documented health data captured over time in an EMR. Although BRFSS data and other large cross-sectional surveys allow for population-based assessment, the health outcome measures examined in these cases are self-reported. . $^{70-16,18}$ Conversely, longitudinal follow-up and access to validated medical diagnoses in several other published studies is limited to populations with access to healthcare either via enrollment in a specific insurance plan or through nationalized healthcare programs. ${ }^{8,9,19-25}$ Survey respondents in the present study were not limited to those covered by a specific healthcare plan, but did have data captured over time in the EMR of regional healthcare provider Marshfield Clinic, providing a unique perspective amongst published ACE studies.

Despite this unique perspective, the percentage of ACEs reported by survey respondents was remarkably similar to other reports from other US populations assessed. The $62 \%$ overall ACE prevalence observed in the Marshfield Clinic catchment area located in northcentral Wisconsin is consistent with prevalence reported elsewhere in the US, ranging from $53 \%$ in Arkansas to $65 \%$ in Washington. ${ }^{18}$ Because ACEs have a clear cumulative effect, with higher ACE scores indicating a greater risk for several health and social problems throughout the lifespan, ${ }^{3}$ ACE scores of four or more are of particular concern. The percentage of respondents in the current study who reported experiencing four or more ACEs was also 
Table 2. Distribution of ACE score by subject demographics and health measures

\begin{tabular}{|c|c|c|c|c|}
\hline & $\begin{array}{c}0 \\
\text { ACEs }\end{array}$ & $\begin{array}{c}1-3 \\
\text { ACEs }\end{array}$ & $\begin{array}{c}4+ \\
\text { ACEs }\end{array}$ & $P$ value \\
\hline Overall & $62 \%$ & $23 \%$ & $15 \%$ & \\
\hline \multicolumn{5}{|l|}{ Demographics } \\
\hline Age (years) & & & & $<0.0001$ \\
\hline $18-34$ & $34 \%$ & $45 \%$ & $21 \%$ & \\
\hline $35-49$ & $26 \%$ & $50 \%$ & $24 \%$ & \\
\hline $50-64$ & $32 \%$ & $47 \%$ & $21 \%$ & \\
\hline$\geq 65$ & $48 \%$ & $47 \%$ & $5 \%$ & \\
\hline Gender & & & & 0.2269 \\
\hline Male & $37 \%$ & $50 \%$ & $13 \%$ & \\
\hline Female & $38 \%$ & $45 \%$ & $17 \%$ & \\
\hline Household Income & & & & 0.0527 \\
\hline$<\$ 25,000$ & $33 \%$ & $45 \%$ & $22 \%$ & \\
\hline$\$ 25,000-34,999$ & $43 \%$ & $41 \%$ & $16 \%$ & \\
\hline$\$ 35,000-49,999$ & $36 \%$ & $50 \%$ & $14 \%$ & \\
\hline$\$ 50,000-74,499$ & $30 \%$ & $55 \%$ & $14 \%$ & \\
\hline$\geq \$ 75,000$ & $42 \%$ & $45 \%$ & $10 \%$ & \\
\hline Education & & & & 0.4342 \\
\hline$<$ High School & $35 \%$ & $46 \%$ & $19 \%$ & \\
\hline High School & $35 \%$ & $47 \%$ & $18 \%$ & \\
\hline Some College & $36 \%$ & $51 \%$ & $13 \%$ & \\
\hline College Degree + & $23 \%$ & $46 \%$ & $31 \%$ & \\
\hline Health Insurance & & & & 0.0001 \\
\hline Private/Medicare & $39 \%$ & $47 \%$ & $13 \%$ & \\
\hline None & $48 \%$ & $39 \%$ & $13 \%$ & \\
\hline Medicaid/BadgerCare & $23 \%$ & $46 \%$ & $31 \%$ & \\
\hline Employment & & & & $<0.0001$ \\
\hline Employed & $31 \%$ & $50 \%$ & $19 \%$ & \\
\hline Out of Work & $32 \%$ & $37 \%$ & $30 \%$ & \\
\hline Retired & $46 \%$ & $49 \%$ & $5 \%$ & \\
\hline \multicolumn{5}{|c|}{ Self-Reported Health Risks and Outcomes } \\
\hline Emotional Supporta & & & & $<0.0001$ \\
\hline Always & $46 \%$ & $43 \%$ & $11 \%$ & \\
\hline Usually & $31 \%$ & $54 \%$ & $15 \%$ & \\
\hline Sometimes & $25 \%$ & $54 \%$ & $21 \%$ & \\
\hline Rarely & $28 \%$ & $31 \%$ & $41 \%$ & \\
\hline Never & $20 \%$ & $50 \%$ & $30 \%$ & \\
\hline Life Satisfaction ${ }^{b}$ & & & & $<0.0001$ \\
\hline Very satisfied & $47 \%$ & $46 \%$ & $7 \%$ & \\
\hline Satisfied & $31 \%$ & $51 \%$ & $18 \%$ & \\
\hline Dissatisfied & $25 \%$ & $35 \%$ & $39 \%$ & \\
\hline Very Dissatisfied & $40 \%$ & $20 \%$ & $40 \%$ & \\
\hline
\end{tabular}




\begin{tabular}{|c|c|c|c|c|}
\hline \multicolumn{4}{|l|}{ General Healthc } & \multirow[t]{2}{*}{$<0.0001$} \\
\hline Excellent & $51 \%$ & $38 \%$ & $11 \%$ & \\
\hline Very good & $40 \%$ & $51 \%$ & $9 \%$ & \\
\hline Good & $35 \%$ & $49 \%$ & $15 \%$ & \\
\hline Fair & $31 \%$ & $44 \%$ & $25 \%$ & \\
\hline Poor & $10 \%$ & $38 \%$ & $52 \%$ & \\
\hline Frequent Mental Distress $^{d}$ & $8 \%$ & $9 \%$ & $26 \%$ & $<0.0001$ \\
\hline Median Days Poor Physical Healthe & 0 & 0 & 2 & $<0.0001$ \\
\hline $\begin{array}{l}\text { Median Days Mental/Physical } \\
\text { Limitatione }^{e}\end{array}$ & 0 & 0 & 3 & $<0.0001$ \\
\hline Smoking & $38 \%$ & $47 \%$ & $68 \%$ & $<0.0001$ \\
\hline Heavy Drinking ${ }^{\dagger}$ & $0 \%$ & $32 \%$ & $80 \%$ & $<0.0001$ \\
\hline \multicolumn{5}{|l|}{ Validated Health Risks and Diagnoses } \\
\hline Median Body Mass Index $\left(\mathrm{mg} / \mathrm{kg}^{2}\right)$ & 29.1 & 29.9 & 30.9 & 0.0220 \\
\hline Depression & $24 \%$ & $35 \%$ & $56 \%$ & $<0.0001$ \\
\hline Anxiety & $19 \%$ & $30 \%$ & $48 \%$ & $<0.0001$ \\
\hline Hypertension & $55 \%$ & $49 \%$ & $39 \%$ & 0.0110 \\
\hline Hypercholesterolemia & $50 \%$ & $49 \%$ & $30 \%$ & 0.0002 \\
\hline Myocardial Infarction & $11 \%$ & $6 \%$ & $7 \%$ & 0.0327 \\
\hline Diabetes Mellitus (type 1 or 2 ) & $18 \%$ & $19 \%$ & $16 \%$ & 0.6088 \\
\hline Heart Disease & $45 \%$ & $43 \%$ & $35 \%$ & 0.1928 \\
\hline Stroke & $7 \%$ & $6 \%$ & $5 \%$ & 0.7437 \\
\hline Asthma & $14 \%$ & $16 \%$ & $41 \%$ & $<0.0001$ \\
\hline Skin Cancer & $12 \%$ & $11 \%$ & $4 \%$ & 0.0406 \\
\hline Other Cancer & $29 \%$ & $30 \%$ & $13 \%$ & 0.0009 \\
\hline Chronic obstructive pulmonary disease & $8 \%$ & $8 \%$ & $13 \%$ & 0.2416 \\
\hline Emphysema & $2 \%$ & $3 \%$ & $2 \%$ & 0.2741 \\
\hline Chronic Bronchitis & $7 \%$ & $7 \%$ & $11 \%$ & 0.2621 \\
\hline Arthritis or Related Condition & $72 \%$ & $70 \%$ & $77 \%$ & 0.3491 \\
\hline
\end{tabular}

Note: Boldface indicates statistical significance $(P<0.05)$ via Chi square test.

aResponse to question "How often to you get the emotional support you need?"

'Response to question "In general, how satisfied are you with your life?"

'Response to question "Would you say that in general your health is -- ?" with choices as indicated.

'Self-reported frequent mental distress is defined as 14 or more bad mental health days in the last 30.

eOver the course of the last month.

fHeavy drinking defined as 5 or more drinks on one occasion for men or 4 or more drinks on one occasion for women in the past 30 days.

MESA, Marshfield Epidemiologic Survey Area; ACE, adverse childhood experience

consistent with previous studies at $15 \%$, falling within the reported range of $12 \%$ in Louisiana to $18 \%$ in Washington. ${ }^{18}$

Consistent with previous studies, ${ }^{13,14,28,30,31}$ ACEs were associated with several negative health and social outcomes, including unemployment, use of public assistance for medical care, lack of emotional support, dissatisfaction with life, poor general and physical health, occurrence of frequent mental distress, limitations cause by mental or physical health issues, smoking, heavy drinking, increased body mass index, and diagnoses of depression, anxiety, and asthma. However, some interesting inverse associations between ACEs and specific medical diagnoses were also noted and have not been reported previously. In the current study, ACE score inversely correlated with diagnoses of hypertension, hypercholesterolemia, heart disease, skin cancer, and other cancers, despite previous reports linking these diseases in adulthood to adverse experiences early in life. ${ }^{24,25,28,32-35}$ There are a number of potential explanations for these findings. For example, participants $\geq 65$ years of age were much less likely to report 


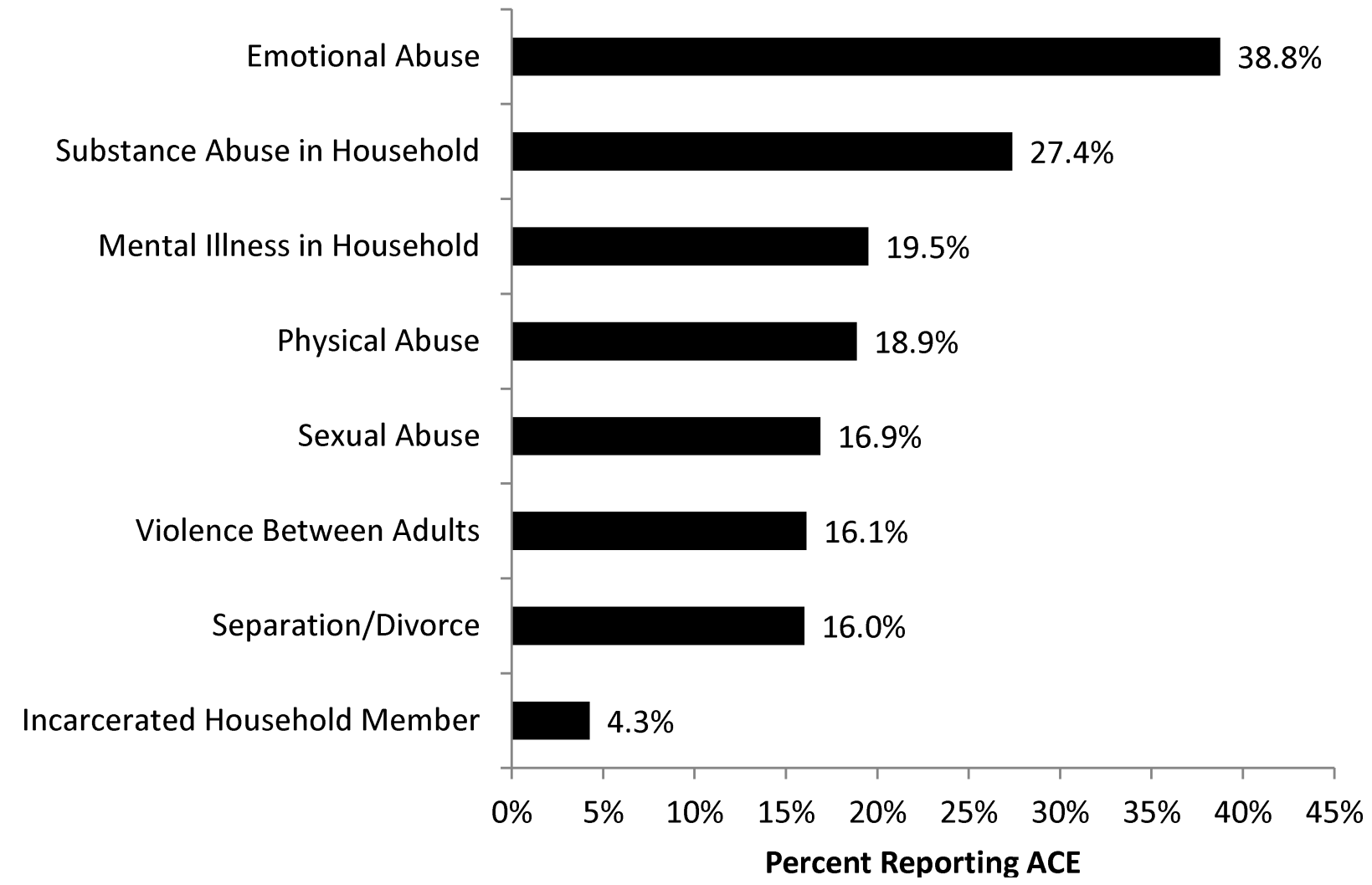

Figure 1. Occurrence of self-reported individual adverse childhood experiences (ACEs) in surveyed population.

four or more ACEs and many of these conditions increase with age. As such, occurrence of diagnosis may be a function of age of the population for conditions such as hypertension, hypercholesterolemia, and myocardial infarction. Given that asthma tends to present at a younger age and there is a clear increase in the proportion of patients with asthma as ACE score increases, this hypothesis is promising. Alternatively, conditions like asthma often necessitate emergency medical attention; whereas, conditions like hypertension and hypercholesterolemia often remain undetected and undiagnosed in a population less likely to receive care. Given the inverse relationship between ACE score and household income and increased likelihood of individuals with ACE scores of four or more to be out-of-work or receiving public assistance for medical care, it may be worthwhile to further investigate the possibility that decreased diagnosis of chronic conditions may be related to underutilization of medical services. Lack of diagnosis and consequent lack of follow-up care for chronic diseases may contribute to the relationship between ACE score and premature death reported by several others. ${ }^{22,25,32}$ Finally, it is worth considering the potential for resilience to adversity in the population, as described further below.

That ACEs impact well-being in adulthood is well understood, but not all individuals who experience adversity in childhood suffer the negative consequences. Resilience to adversity was once considered an innate trait of exceptional individuals, but more recent evidence suggests that resilience resources and well-timed interventions to promote resilience can ameliorate the negative effects of ACEs by promoting individual coping skills. ${ }^{36-41}$ Given that healthcare systems serving rural populations have long struggled to implement evidence-based practices for traumatic stress in childhood, ${ }^{42}$ the potential role of resilience in mediating the observed inverse relationships between ACEs and certain diseases presents an interesting prospect that, along with other alternative explanations for the inverse relationships between ACEs and specific diagnoses observed here, warrants further investigation. Tools for measuring resilience are becoming increasingly available and results following employment in various populations will undoubtedly prove interesting. ${ }^{43}$

The notion of how different types of ACEs affect future health outcomes is of great interest. For example, emotional abuse during childhood was reported by $38.8 \%$ of survey respondents, considerably higher than any other report to date, ranging from $11 \%$ in the southern California Kaiser Permanente study published by Felitti et $\mathrm{al}^{3}$ in 1998 to $34.9 \%$ in the state of Washington as published by the CDC in $2010 .{ }^{18}$ Even in the statewide Wisconsin survey, emotional abuse was reported by only $29 \%$ of participants..$^{13}$ How this high rate of emotional abuse might impact our specific population is of great interest. However, the data presented here suggest that little difference can be gleaned by separation of ACEs into categories of direct abuse and household dysfunction. In doing so, only a relationship with chronic bronchitis and household dysfunction emerged. Given that the two categories examined, namely 


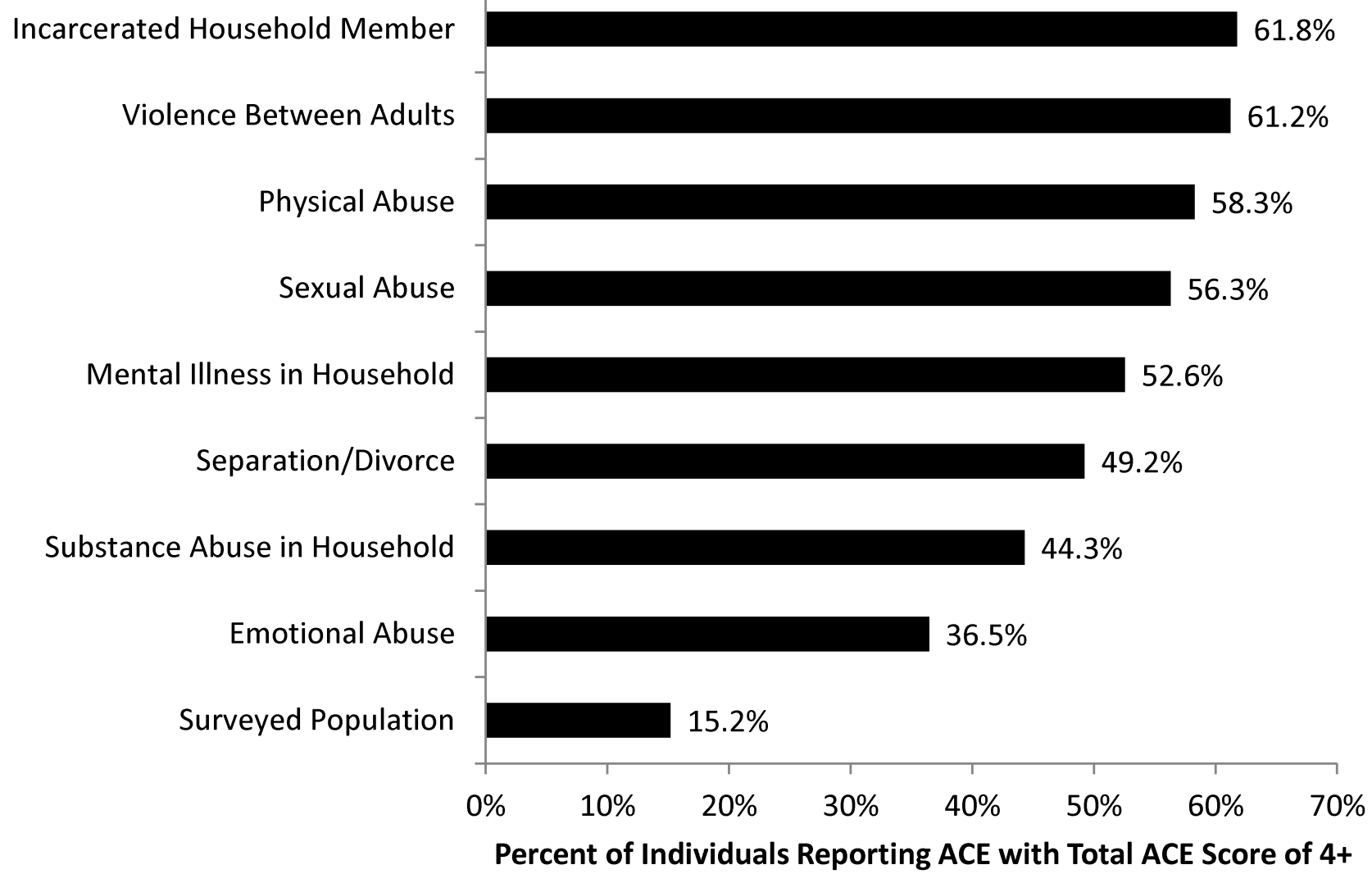

Figure 2. Percentage of respondents that reported experiencing each adverse childhood experience (ACE) with a total ACE score of $\geq 4$ demonstrating that ACEs tend to cluster. Overall percentage of survey respondents reporting four or more ACEs is shown for comparison.

direct abuse and household dysfunction, are not mutually exclusive and the propensity for ACE co-occurrence, it is perhaps not surprising that meaningful differences were not observed. All ACEs cause toxic stress, and it is this milieu, influenced by the number of ACEs experienced rather than type, that ultimately results in negative outcomes without appropriate early intervention and development of resilience. ${ }^{2}$

While previously reported ACE studies have been linked to validated outcomes, such as diagnoses and prescription records, this is the first study to link self-reported ACEs from a community-based population to comprehensive clinical data on health outcomes. The accuracy of medical data captured by self-report can be questionable, and sampling from amongst an insured and/or healthcare seeking population is unlikely to be completely representative of a population. The results presented here combine both broad sampling from within the community and data from a validated EMR to confirm findings from previous studies related to the relationship between ACE and poor mental and physical health outcomes in adulthood, while also demonstrating interesting inverse relationships between ACEs and diagnoses of hypertension, hypercholesterolemia, myocardial infarction, and skin or other cancers. Further exploration of the inverse relationships between ACEs and important clinical diagnoses in this population would be particularly interesting. Of course, as with other ACE studies, we are still reliant on self-report for documentation of ACEs and may not have considered all potential ACEs, as we used only those described by the BRFSS questionnaire. Future longitudinal studies following individuals with documented ACEs over time, direct comparison of ACE-related outcomes in rural and urban populations, or expanded consideration of what constitutes an ACE are warranted.

\section{References}

1. Anda RF, Felitti VJ, Bremner JD, Walker JD, Whitfield C, Perry BD, Dube SR, Giles WH. The enduring effects of abuse and related adverse experiences in childhood. A convergence of evidence from neurobiology and epidemiology. Eur Arch Psychiatry Clin Neurosci 2006; 256:174-186.

2. McCrory E, De Brito SA, Viding E. The impact of childhood maltreatment: a review of neurobiological and genetic factors. Front Psychiatry 2011;2:48.

3. Felitti VJ, Anda RF, Nordenberg D, Williamson DF, Spitz AM, Edwards V, Koss MP, Marks JS. Relationships of childhood abuse and household dysfunction to many of the leading causes of death in adults. Am J Prev Med. 1998;14:245 258.

4. Finkelhor D, Shattuck A, Turner H, Hamby S. Improving the adverse childhood experiences study scale. JAMA Pediatr. 2013;167:70-75. 
Table 3. Distribution of direct abuse and household dysfunction by subjects demographics and health measures

\begin{tabular}{|c|c|c|c|c|c|c|}
\hline & \multicolumn{3}{|c|}{ Direct abuse $^{a}$} & \multicolumn{3}{|c|}{ Household dysfunction ${ }^{b}$} \\
\hline & Yes & No & $P$ value & Yes & No & $P$ value \\
\hline \multicolumn{7}{|l|}{ Demographics } \\
\hline Age (years) & & & $<0.0001$ & & & $<0.0001$ \\
\hline $18-34$ & $50 \%$ & $50 \%$ & & $54 \%$ & $46 \%$ & \\
\hline $35-49$ & $62 \%$ & $38 \%$ & & $59 \%$ & $46 \%$ & \\
\hline $50-64$ & $53 \%$ & $47 \%$ & & $52 \%$ & $48 \%$ & \\
\hline$\geq 65$ & $35 \%$ & $65 \%$ & & $36 \%$ & $64 \%$ & \\
\hline Gender & & & 0.8731 & & & 0.9294 \\
\hline Male & $46 \%$ & $54 \%$ & & $47 \%$ & $53 \%$ & \\
\hline Female & $47 \%$ & $53 \%$ & & $47 \%$ & $53 \%$ & \\
\hline Household Income & & & 0.2695 & & & 0.0991 \\
\hline$<\$ 25,000$ & $53 \%$ & $47 \%$ & & $50 \%$ & $50 \%$ & \\
\hline$\$ 25,000-34,999$ & $43 \%$ & $57 \%$ & & $46 \%$ & $54 \%$ & \\
\hline$\$ 35,000-49,999$ & $48 \%$ & $52 \%$ & & $50 \%$ & $50 \%$ & \\
\hline$\$ 50,000-74,499$ & $51 \%$ & $49 \%$ & & $56 \%$ & $44 \%$ & \\
\hline$\geq \$ 75,000$ & $42 \%$ & $58 \%$ & & $38 \%$ & $62 \%$ & \\
\hline Education & & & 0.8246 & & & 0.3746 \\
\hline$<$ High School & $47 \%$ & $53 \%$ & & $50 \%$ & $50 \%$ & \\
\hline High School & $49 \%$ & $51 \%$ & & $49 \%$ & $51 \%$ & \\
\hline Some College & $47 \%$ & $53 \%$ & & $49 \%$ & $51 \%$ & \\
\hline College Degree + & $45 \%$ & $55 \%$ & & $42 \%$ & $58 \%$ & \\
\hline Health Insurance & & & 0.0073 & & & 0.1520 \\
\hline Private/Medicare & $45 \%$ & $55 \%$ & & $45 \%$ & $55 \%$ & \\
\hline None & $39 \%$ & $61 \%$ & & $48 \%$ & $52 \%$ & \\
\hline Medicaid/BadgerCare & $62 \%$ & $38 \%$ & & $56 \%$ & $44 \%$ & \\
\hline Employment & & & 0.0002 & & & $<0.0001$ \\
\hline Employed & $52 \%$ & $48 \%$ & & $54 \%$ & $46 \%$ & \\
\hline Out of Work & $56 \%$ & $44 \%$ & & $60 \%$ & $40 \%$ & \\
\hline Retired & $38 \%$ & $62 \%$ & & $36 \%$ & $64 \%$ & \\
\hline \multicolumn{7}{|c|}{ Self-Reported Health Risks and Outcomes } \\
\hline Emotional Support ${ }^{\mathrm{c}}$ & & & $<0.0001$ & & & $<0.0001$ \\
\hline Always & $37 \%$ & $63 \%$ & & $38 \%$ & $62 \%$ & \\
\hline Usually & $49 \%$ & $51 \%$ & & $52 \%$ & $48 \%$ & \\
\hline Sometimes & $63 \%$ & $37 \%$ & & $66 \%$ & $34 \%$ & \\
\hline Rarely & $69 \%$ & $31 \%$ & & $51 \%$ & $49 \%$ & \\
\hline Never & $60 \%$ & $40 \%$ & & $60 \%$ & $40 \%$ & \\
\hline Life Satisfaction $^{d}$ & & & $<0.0001$ & & & 0.0022 \\
\hline Very satisfied & $34 \%$ & $66 \%$ & & $39 \%$ & $61 \%$ & \\
\hline Satisfied & $54 \%$ & $46 \%$ & & $53 \%$ & $47 \%$ & \\
\hline Dissatisfied & $73 \%$ & $27 \%$ & & $51 \%$ & $49 \%$ & \\
\hline Very Dissatisfied & $40 \%$ & $60 \%$ & & $60 \%$ & $40 \%$ & \\
\hline
\end{tabular}




\begin{tabular}{|c|c|c|c|c|c|c|}
\hline \multicolumn{2}{|l|}{ General Healthe } & \multicolumn{3}{|c|}{$<0.0001$} & & \multirow[t]{2}{*}{$<0.0001$} \\
\hline Excellent & $33 \%$ & $67 \%$ & & $37 \%$ & $63 \%$ & \\
\hline Very good & $40 \%$ & $60 \%$ & & $45 \%$ & $55 \%$ & \\
\hline Good & $51 \%$ & $49 \%$ & & $46 \%$ & $54 \%$ & \\
\hline Fair & $55 \%$ & $45 \%$ & & $54 \%$ & $46 \%$ & \\
\hline Poor & $79 \%$ & $21 \%$ & & $86 \%$ & $14 \%$ & \\
\hline Frequent Mental Distress ${ }^{\dagger}$ & $15 \%$ & $8 \%$ & 0.0013 & $15 \%$ & $8 \%$ & 0.0020 \\
\hline Mean Days Poor Physical Health ${ }^{g}$ & 6.0 & 3.6 & $<0.0001$ & 5.9 & 3.7 & $<0.0001$ \\
\hline Mean Days Mental/Physical Limitation ${ }^{g}$ & 5.0 & 2.7 & $<0.0001$ & 5.0 & 2.7 & $<0.0001$ \\
\hline Smoking & $53 \%$ & $41 \%$ & 0.0008 & $56 \%$ & $36 \%$ & $<0.0001$ \\
\hline Heavy Drinkingh & $41 \%$ & $15 \%$ & $<0.0001$ & $58 \%$ & $0 \%$ & $<0.0001$ \\
\hline \multicolumn{7}{|l|}{ Validated Health Risks and Diagnoses } \\
\hline Median Body Mass Index (mg/kg²) & 30.3 & 29.0 & 0.0033 & 30.4 & 29.1 & 0.0020 \\
\hline Depression & $44 \%$ & $25 \%$ & $<0.0001$ & $43 \%$ & $26 \%$ & $<0.0001$ \\
\hline Anxiety & $39 \%$ & $20 \%$ & $<0.0001$ & $35 \%$ & $23 \%$ & 0.0001 \\
\hline Hypertension & $47 \%$ & $53 \%$ & 0.1040 & $45 \%$ & $54 \%$ & 0.0073 \\
\hline Hypercholesterolemia & $40 \%$ & $52 \%$ & 0.0009 & $44 \%$ & $49 \%$ & 0.1248 \\
\hline Myocardial Infarction & $6 \%$ & $10 \%$ & 0.0274 & $7 \%$ & $9 \%$ & 0.3413 \\
\hline Diabetes Mellitus (type 1 or 2) & $19 \%$ & $18 \%$ & 0.7928 & $19 \%$ & $18 \%$ & 0.5975 \\
\hline Heart Disease & $41 \%$ & $44 \%$ & 0.5185 & $40 \%$ & $45 \%$ & 0.1617 \\
\hline Stroke & $6 \%$ & $6 \%$ & 0.7812 & $5 \%$ & $7 \%$ & 0.3509 \\
\hline Asthma & $23 \%$ & $15 \%$ & 0.0027 & $25 \%$ & $14 \%$ & $<0.0001$ \\
\hline Skin Cancer & $9 \%$ & $12 \%$ & 0.1188 & $7 \%$ & $13 \%$ & 0.0105 \\
\hline Other Cancer & $24 \%$ & $30 \%$ & 0.0742 & $22 \%$ & $31 \%$ & 0.0105 \\
\hline Chronic obstructive pulmonary disease & $10 \%$ & $9 \%$ & 0.6311 & $11 \%$ & $7 \%$ & 0.0328 \\
\hline Emphysema & $3 \%$ & $1 \%$ & 0.7605 & $3 \%$ & $2 \%$ & 0.7865 \\
\hline Chronic Bronchitis & $8 \%$ & $8 \%$ & 0.8713 & $10 \%$ & $6 \%$ & 0.0276 \\
\hline Arthritis or Related Condition & $73 \%$ & $71 \%$ & 0.5917 & $72 \%$ & $72 \%$ & 0.8438 \\
\hline \multicolumn{7}{|c|}{$\begin{array}{l}\text { Note: Boldface indicates statistical significance }(P<0.05) \text { via Chi square test. } \\
\text { Direct abuse is defined as an indication of at least one of the following: emotional, physical, or sexual abuse }\end{array}$} \\
\hline \multicolumn{7}{|c|}{$\begin{array}{l}\text { Direct abuse is defined as an indication of at least one of the following: emotional, physical, or sexual abuse } \\
\text { Household dysfunction is defined as an indication of at least one of the following: mental illness, incarceration, violence, substance abuse, } \\
\text { or divorce or separation in the household }\end{array}$} \\
\hline \multicolumn{7}{|c|}{ Response to question "How often to you get the emotional support you need?" } \\
\hline \multicolumn{7}{|c|}{ Response to question "In general, how satisfied are you with your life?" } \\
\hline \multicolumn{7}{|c|}{$\begin{array}{l}\text { Response to question "Would you say that in general your health is -- ?" with choices as indicated. } \\
\text { Self-reported frequent mental distress is defined as } 14 \text { or more bad mental health days in the last } 36\end{array}$} \\
\hline \multicolumn{7}{|l|}{$\begin{array}{l}\text { Self-reported frequent mental distres } \\
\text { Over the course of the last month. } \\
\text { Heavy drinking defined as } 5 \text { or more }\end{array}$} \\
\hline
\end{tabular}

5. Cronholm PF, Forke CM, Wade R, Bair-Merritt MH, Davis M, Harkins-Schwarz M, Pachter LM, Fein JA. Adverse childhood experiences: expanding the concept of adversity. Am J Prev Med 2015;49:354-361.

6. Wade R Jr, Cronholm PF, Fein JA, Forke CM, Davis MB, Harkins-Schwarz M, Pachter LM, Bair-Merritt MH. Household and community-level adverse childhood experiences and adult health outcomes in a diverse urban population. Child Abuse Negl 2016;52:135-145.
7. Bellis MA, Lowey H, Leckenby, Hughes K, Harrison D. Adverse childhood experiences: retrospective study to determine their impact on adult health beheaviours and health outcomes in a UK population. J Public Health (Oxf) 2014;36:81-91.

8. Björkenstam E, Hjern A, Mittendorfer-Rutz E, Vinnerljung B, Hallqvist J, Ljung R. Multi-exposure and clustering of adverse childhood experiences, socioeconomic differences and psychotropic medication in young adults. PLoS One 2013;8:e53551. 
9. Björkenstam E, Dalman C, Winnerljung B, Weitoft GR, Walder DJ, Burström B. Childhood household dysfunction, school performance and psychiatric care utilization in young adults: a register study of 96399 individuals in Stockholm County. J Epidemiol Community Health 2015 Dec 8. [Epub ahead of print]

10. Brown MJ, Thacker LR, Cohen SA. Association between adverse childhood experiences and diagnosis of cancer. PLoS One 2013;8:e65524.

11. Bruskas D, Tessin DH. Adverse childhood experiences and psychosocial well-being of women who were in foster care as children. Perm J 2013; 17:e131-e141.

12. Chapman DP, Liu Y, Presley-Cantrell LR, Edwards VJ, Wheaton AG, Perry GS, Croft JB. Adverse childhood experiences and frequent insufficient sleep in 5 U.S. States, 2009: a retrospective cohort study. BMC Public Health 2013;13:3.

13. O'Connor C, Finkbiner C, Watson L. Adverse Childhood Experiences in Wisconsin: Findings from the 2010 Behavioral Risk Factor Survey. Madison, WI: Wisconsin Children's Trust Fund and Child Abuse Prevention Fund of Children's Hospital and Health System. 2012. Available at: http://wichildrenstrustfund.org/files/WisconsinACEs.pdf. Accessed February 5, 2014.

14. Pretty C, O'Leary DD, Cairney J, Wade TJ. Adverse childhood experiences and the cardiovascular health of children: a cross-sectional study. BMC Pediatr 2013;13:208.

15. Roos LE, Mota N, Afifi TO, Katz LY, Distasio J, Sareen J. Relationship between adverse childhood experiences and homelessness and the impact of axis I and II disorders. Am J Public Health 2013;103:S275-S281.

16. Schüssler-Firoenza Rose SM, Xie D, Stineman M. Adverse childhood experiences and disability in U.S. adults. PM R 2014;6:670-680.

17. Larkin H, Shields JJ, Anda RF. The health and social consequences of adverse childhood experiences (ACE) across the lifespan: an introduction to prevention and intervention in the community. J Prev Interv Community 2012;40:263-270.

18. Centers for Disease Control and Prevention (CDC). Adverse childhood experiences reported by adults --- five states, 2009. MMWR Morb Mortal Wkly Rep. 2010;59:1609-1613.

19. Anda RF, Brown DW, Dube SR, Bremner JD, Felitti VJ, Giles WH. Adverse childhood experiences and chronic obstructive pulmonary disease in adults. Am J Prev Med. 2008;34:396403.

20. Anda RF, Brown DW, Felitti VJ, Dube SR, Giles WH. Adverse childhood experiences and prescription drug use in a cohort study of adult HMO patients. BMC Public Health 2008;8:198.

21. Brown DW, Anda RF, Felitti VJ, Edwards VJ, Malarcher AM, Croft JB, Giles WH. Adverse childhood experiences are associated with the risk of lung cancer: a prospective cohort study. BMC Public Health 2010;10:20.

22. Brown DW, Anda RF, Tiemeier H, Felitti VJ, Edwards VJ, Croft JB, Giles WH. Adverse childhood experiences and the risk of premature mortality. Am J Prev Med. 2009;37:389 396.

23. Dube SR, Fairweather D, Pearson WS, Felitti VJ, Anda RF, Croft JB. Cumulative childhood stress and autoimmune diseases in adults. Psychosom Med 2009;71:243-250.

24. Kelly-Irving M, Lepage B, Dedieu D, Lacey R, Cable N, Bartley M, Blane D, Grosclaude P, Lang T, Delpierre C. Childhood adversity as a risk for cancer: findings from the 1958 British birth cohort study. BMC Public Health 2013;13:767.
25. Kelly-Irving M, Lepage B, Dedieu D, Bartley M, Blane D, Grosclaude P, Lang T, Delpierre C. Adverse childhood experiences and premature all-cause mortality. Eur J Epidemiol 2013;28:721-734.

26. DeStefano F, Eaker ED, Broste SK, Nordstrom DL, Peissig PK, Vierkant RA, Konitzer KA, Grober RL, Layde PM. Epidemiologic research in an integrated regional medical care system: the Marshfield Epidemiologic Study Area. J Clin Epidemiol 1996;49:643-652.

27. Kieke AL, Kieke BA Jr, Kopitzke SL, McClure DL, Belongia EA, VanWormer JJ, Greenlee RT. Validation of health event capture in the Marshfield Epidemiologic Study Area. Clin Med Res 2015;13:103-111.

28. Gilbert LK, Breiding MJ, Merrick MT, Thompson WW, Ford DC, Dhingra SS, Parks SE. Childhood adversity and adult chronic disease: an update from ten states and the District of Columbia, 2010. Am J Prev Med. 2015;48:345-349.

29. Logan-Greene P, Green S, Nurius PS, Longhi D. Distinct contributions of adverse childhood experiences and resilience resources: a cohort analysis of adult physical and mental health. Soc Work Health Care 2014;53:776-797.

30. Heim C, Nemeroff CB. The role of childhood trauma in the neurobiology of mood and anxiety disorders: preclinical and clinical studies. Biol Psychiatry 2001;49:1023-1039.

31. Hemmingsson E, Johansson K, Reynisdottir S. Effects of childhood abuse on adult obesity: a systematic review and meta-analysis. Obes Rev 2014;15:882-893.

32. Bellis MA, Hughes K, Leckenby N, Hardcastle KA, Perkins C, Lowey H. Measuring mortality and the burden of adult disease associated with adverse childhood experiences in England: a national survey. J Public Health (Oxf). 2015;37:445-454

33. Danese A, Moffitt TE, Harrington H, Milne BJ, Polanczyk G, Pariante CM, Poulton R, Caspi A. Adverse childhood experiences and adult risk factors for age-related disease: depression, inflammation, and clustering of metabolic risk factors. Arch Pediatr Adolesc Med. 2009;163:1135-1143.

34. Dong M, Giles WH, Felitti VJ, Dube SR, Williams JE, Chapman DP, Anda RF. Insights into causal pathways for ischemic heart disease: adverse childhood experiences study. Circulation 2004;110:1761-1766.

35. Su S, Wang X, Kapuku GK, Treiber FA, Pollock DM, Harshfield GA, McCall WV, Pollock JS. Adverse childhood experiences are associated with detrimental hemodynamics and elevated circulating endothelin- 1 in adolescents and young adults. Hypertension 2014;64:201 207.

36. Bellis MA, Hughes K, Leckenby N, Perkins C, Lowey H. National household survey of adverse childhood experiences and their relationship with resilience to health-harming behaviors in England. BMC Med 2014;12:72.

37. Bethell C, Gombojav N, Solloway M, Wissow L. Adverse childhood experiences, resilience and mindfulness-based approaches: common denominator issues for children with emotional, mental, or behavioral problems. Child Adolesc Psychiatr Clin N Am 2016;25:139-156.

38. Chandler GE, Roberts SJ, Chiodo L. Resilience intervention for young adults with adverse childhood experiences. J Am Psychiatr Nurses Assoc 2015;21:406-416.

39. Larkin H, Felitti VJ, Anda RF. Social work and adverse childhood experiences research: implications for practice and health policy. Soc Work Public Health 2014;29:1-16.

40. Larkin H, Beckos BA, Shields JJ. Mobilizing resilience and recovery in response to adverse childhood experiences (ACE): a restorative integral support (RIS) case study. J Prev Interv Community 2012;40:335-346. 
41. Nurius PS, Green S, Logan-Greene P, Borja S. Life course pathways of adverse childhood experiences toward adult psychological well-being: a stress process analysis. Child Abuse Negl 2015;45:143-153.

42. Paul LA, Gray MJ, Elhai JD, Massad PM, Stamm BH. Promotion of evidence-based practices for child traumatic stress in rural populations: identification of barriers and promising solutions. Trauma Violence Abuse 2006;7:260-273.

43. Ungar M. Practitioner review: diagnosing childhood resilience - a systemic approach to the diagnosis of adaptation in adverse social and physical ecologies. J Child Psychol Psychiatry 2015;56:4-17.

\section{Author Affiliations}

Kristen C. Iniguez, DO* and Rachel V. Stankowski, PhD†, $\neq$

*Child Advocacy Center and Department of Pediatrics, Marshfield Clinic, Marshfield, Wisconsin, USA

†Marshfield Clinic Research Foundation, Marshfield, Wisconsin, USA

+Current affiliation: Marshfield Clinic Center for

Community Outreach, Marshfield, Wisconsin, USA 